\title{
Energy intakes of children and adolescents with anorexia nervosa during in-patient refeeding
}

\author{
C. Carr ${ }^{1}$, M. O’Reilly ${ }^{2}$, M Anglim ${ }^{3}$ and S. Sugrue ${ }^{1}$ \\ ${ }^{1}$ Dublin Institute of Technology, Kevin Street, Dublin 8, Republic of Ireland, ${ }^{2}$ Nutrition and Dietetic Department, Children's \\ University Hospital, Temple Street, Dublin 1, Republic of Ireland and ${ }^{3}$ St. Francis Clinic, Children's University Hospital, \\ Temple Street, Dublin 1, Republic of Ireland
}

In-patient nutritional intervention for children and adolescents with anorexia nervosa (AN) initially involves the process of refeeding ${ }^{(1)}$. Refeeding is the cautious provision of adequate energy to achieve weight gain ${ }^{(1)}$. The aim of refeeding is to achieve medical and cognitive stability to facilitate recovery ${ }^{(1,2)}$. The recommended rate of weight gain is 0.5 to $1.0 \mathrm{~kg} / \mathrm{wk}^{(2)}$, however, energy requirements to achieve this have not been established to date ${ }^{(1)}$. As a result, current recommendations are based on expert opinion rather than evidence ${ }^{(1)}$, and can range from 2000 to $7000 \mathrm{kcal} / \mathrm{d}(8373 \text { to } 29307 \mathrm{~kJ} / \mathrm{d})^{(3,4)}$. The primary aim of this study was to investigate actual energy intakes and subsequent weight gain in children and adolescents with AN during in-patient refeeding.

This study was a retrospective clinical audit of a sample of 12 children and adolescents with AN aged 11 to 15 years, admitted to a children's university teaching hospital between 2005 and 2011 for in-patient refeeding. Prescribed and reported food intakes and weight records, over the first four weeks of treatment, were collected from detailed food record charts completed by nursing staff, and analysed using Tinuviel, WISP v3.0 nutritional analysis software (Warrington, UK).
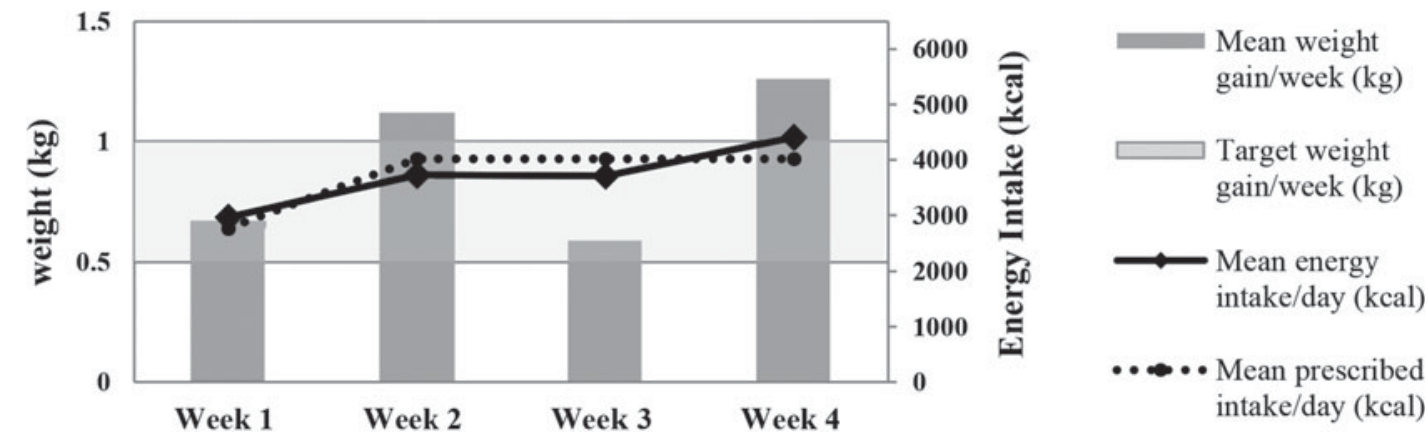

Mean prescribed energy intake over the first four weeks of refeeding ranged from $2772 \mathrm{kcal} / \mathrm{d}(11605 \mathrm{~kJ} / \mathrm{d})$ over week one, to $4013 \mathrm{kcal} / \mathrm{d}$ $(16801 \mathrm{~kJ} / \mathrm{d})$ over weeks two to four. Compliance with individualised prescribed diet was achieved with mean reported energy intake ranging from $2964 \mathrm{kcal} / \mathrm{d}(12401 \mathrm{~kJ} / \mathrm{d})$ over week one, to $4406 \mathrm{kcal} / \mathrm{d}(18447 \mathrm{~kJ} / \mathrm{d})$ over week four. The target weight gain of 0.5 to $1 \mathrm{~kg} /$ wk was achieved with corresponding mean weight gain values ranging from 0.59 to $1.26 \mathrm{~kg}$.

These energy intake values conform with recommendations from expert groups for refeeding in AN, and significantly exceed published energy requirements for healthy children and adolescents of similar age (11 to 18 years) and gender, which range from 1845 to $2755 \mathrm{kcal} / \mathrm{d}(7724 \text { to } 11534 \mathrm{~kJ} / \mathrm{d})^{(5)}$.

Results from this study suggest that energy intakes of 3000 to $4500 \mathrm{kcal} / \mathrm{d}$ (12 560 to $18840 \mathrm{~kJ} / \mathrm{d}$ ) can achieve effective weight gain in children and adolescents with AN during refeeding.

1. Royal College of Psychiatrists (2005) Guidelines for the nutritional management of anorexia nervosa. Council Report CR130. London: RC Psych.

2. Junior MARSIPAN working group (2012) Management of really sick patients with anorexia nervosa. Royal College of Psychiatrists London: Council Report CR162.

3. American Psychiatric Association (2006) Practice guideline for the treatment of patients with eating disorders, third edition. Am J Psychiatry 1, 4-54.

4. National Institute for Health and Clinical Excellence (2004) Eating disorders: core interventions in the treatment and management of anorexia nervosa, bulimia nervosa and related eating disorders. NICE: Clinical Guideline CG9. http://www.nice.org.uk/CG009NICEguideline.

5. Great Ormond Street (2009) Nutritional requirements for children in health and disease. Great Ormond Street Hospital for Children NHS Trust. $4^{\text {th }}$ ed. Dietetic Department, Great Ormond Street Hospital. 